\title{
Virulence and Diversity of Blumeria graminis f. sp. hordei in Israel and in the Czech Republic
}

\author{
Antonín Dreiseitl, Agricultural Research Institute Kroměříž Ltd., Havlíčkova 2787, CZ-76701 Kroměříž, Czech \\ Republic; Amos Dinoor, Department of Plant Pathology and Microbiology, The Faculty of Agricultural, Food and \\ Environmental Quality Sciences, Rehovot IL-76100, The Hebrew University of Jerusalem, Israel; and Evsey Kosman, \\ Institute for Cereal Crops Improvement, The George S. Wise Faculty for Life Sciences, Tel Aviv University, Tel Aviv \\ IL-69978, Israel
}

\begin{abstract}
Dreiseitl, A., Dinoor, A., and Kosman, E. 2006. Virulence and diversity of Blumeria graminis $\mathrm{f}$. sp. hordei in Israel and in the Czech Republic. Plant Dis. 90:1031-1038.

Three hundred and nine isolates were obtained from three natural populations of Blumeria graminis f. sp. hordei occurring on wild barley (Hordeum vulgare subsp. spontaneum) at two locations in Israel during 1997 and 1999. Their virulence frequency was determined on 32 differential lines. No isolate was virulent on the differential lines possessing the genes Mla13, mlo, $M l f 1$, and $M l i$, and conversely no isolate was avirulent on the differential lines possessing the genes MlRu2, MlLa, Mlh, Mla8, Mla25, and Mlj. The frequencies of isolates overcoming the genes Mlg, Mla7, and Mla27 were 0 to $16 \%$ at individual locations; frequencies of isolates overcoming the genes Mla9, Mla17, and Mla18 ranged from 37 to $78 \%$, and frequencies of virulences to genes Mla1, Mla3, Mla6, Mlp1, Mlat, Mla12, Mlra, Mlk1, Mla19, Mla20, Mla26, Mla28, Mla29, Mla30, Mla32, and mlt1 were 79 to $99 \%$. Based on examination of 376 isolates collected in the same years from the Czech Republic, these populations differed greatly from the Israeli ones. The Czech populations showed greater diversity of virulence and lower mean virulence complexity than the Israeli populations. Diversity in the Israeli populations differed also among clusters of niches at the same location.
\end{abstract}

Additional keywords: barley powdery mildew, Erysiphe graminis f. sp. hordei

Barley (Hordeum vulgare L.) is a minor crop in Israel, rarely exceeding an area of 1,500 ha. Most of it is grown in the more arid part of the country (northern part of Negev and the Jordan Valley). Spring barley is the only crop grown and is sown in late autumn (November to December) and harvested in spring (April to May). The cultivars are of local origin, and powdery mildew resistance has not been a selection criterion in breeding programs. Wild barley (Hordeum vulgare subsp. spontaneum (C. Koch.)) is not a predominant component of the wild plant communities, but it occurs widely in disturbed habitats throughout Israel. There are also particular localities where wheat is mainly grown and in which wild barley has become a very hard-to-control weed.

Barley powdery mildew, caused by Blumeria graminis DC. f. sp. hordei Ém. Marchal, is a windborne, biotrophic, fungal pathogen of cultivated barley and wild barley. It is particularly prevalent under

Corresponding author: A. Dreiseitl
E-mail: dreiseitl@vukrom.cz

Accepted for publication 8 March 2006.

DOI: 10.1094/PD-90-1031

(C) 2006 The American Phytopathological Society cool conditions when the maximum daily temperature does not exceed $25^{\circ} \mathrm{C}$. The life cycle of the pathogen in Israel is closely linked with seasonal cycles (26). $B$. graminis f. sp. hordei survives summer as immature cleistothecia on dead leaves of barley until lower temperatures and autumn rains trigger the maturation of the cleistothecia and release of their ascospores. Maturation of cleistothecia coincides with the germination of barley seeds in the autumn. Epidemics of powdery mildew start from foci produced by the released ascospores, and develop via the conidial stage throughout winter and early spring. The change of day length at the beginning of spring induces cleistothecia formation. The pathogen remains dormant, as immature cleistothecia containing asci but no ascospores, until the next autumn. The sexual stage increases genetic diversity and is the source of primary inoculum. The population of B. graminis f. sp. hordei in Israel has co-existed and developed in association with wild barley rather than with cultivated barley.

Growing resistant cultivars is an economical and environmentally safe way of protecting barley against powdery mildew. Wild barley is a rich source of mildew resistance $(10,14,21)$ and is crosscompatible with cultivated barley. The Fertile Crescent is the center of origin, diversity, and domestication of wild barley, and many resistance genes are derived from wild barley originating from the Eastern Mediterranean. It is likely, therefore, that the pathogen has accumulated genes for virulence that will overcome resistance genes found in this region $(6,7)$. Indeed, resistances found here are often ineffective against most pathogen strains found elsewhere $(6,7)$. On the other hand, in parts of Europe where these resistance genes have recently been introduced into commercial cultivars, they are still effective. Therefore, barley breeders in Europe often use sources of resistance to powdery mildew from wild barley originating from Israel. The overall goal of this study was to verify the assumptions behind this practice by comparing virulence characteristics of B. graminis f. sp. hordei populations from Israel with other European populations, taking into account the fact that the Israeli populations infect diverse populations of wild barley. Specific objectives were: (i) to characterize Israeli B. graminis f. sp. hordei populations using standard European differentials (30) as well as standard barley lines carrying "new" resistance genes of wild barley to powdery mildew $(20,21,23$, 24,36 ); (ii) to compare these Israeli populations with populations from the Czech Republic; and (iii) to evaluate and assess diversity in and genetic distances among $B$. graminis $\mathrm{f}$. sp. hordei populations by using various measures of genetic diversity and genetic distances. The Czech Republic was selected as representative of Europe because it is situated in the middle of the Central European part of the continent, barley is an important crop grown throughout the country with the second highest land area planted of all crops grown there, both spring and winter barley types are grown, and most cultivars grown possess the same resistance genes as those planted in neighboring countries. Czech $B$. graminis $\mathrm{f}$. sp. hordei populations are expected to be similar to those in other countries in the Central European region because of pathogen migration in the region as well as cultivars with similar resistance genes.

\section{MATERIALS AND METHODS}

All tests for virulence of the Israeli populations were carried out at the Faculty of Agricultural, Food and Environmental 
Quality Sciences, Rehovot, Israel. All tests for virulence of the Czech populations were carried out at the Agricultural Research Institute Kroměříž Ltd. in the Czech Republic.

Location of Israeli B. graminis f. sp. hordei populations. Isolates of the pathogen were sampled at two locations. The first was at Ashquelon in a national park situated on the Mediterranean Sea coast, which is on the Southern Coastal Plain in Israel. This is a disturbed plant community, which contains many plants, like wild barley, that can swiftly colonize bare ground. The second location was at Har'el (Judean Foothills) in and around a small grove of pine trees near cultivated fields, but without cultivated barley. This is also a disturbed plant community, with profuse stands of wild barley. Har'el is about 50 $\mathrm{km}$ northeast of Ashquelon.

Spatial distribution of the niches sampled at the Israeli locations. Both the Ashquelon and Har'el locations include many separate niche environments. The isolates were sampled from different niches in approximately equal proportions to obtain representative samples for both locations.

Nineteen niche sites at Ashquelon covered a 250-m transect from the cliffs of the coast toward the east. For data analyses, these niches were clustered in four groups according to topography and vegetation. The clusters were: a (the one closest to the cliffs), b, c, and $\mathbf{d}$ (the most eastern collection site). The tallest plants in the area were trees $5 \mathrm{~m}$ high in the east, and bushes 1 to $2 \mathrm{~m}$ high scattered throughout the rest of the area.

The 17 to 20 niche environments at Har'el were dispersed within and around a small pine wood comprising tall trees. Exchange of conidia among niches was, therefore, quite limited. For analyzing data, these niche sites were clustered in four groups. Cluster b included niches among the trees at the northern fringe of the small forest. Cluster $\mathbf{d}$ included niches at the southern fringe of the wood. This distribution has some importance in understanding the data because shading increases the development of $B$. graminis $\mathrm{f}$. sp. hordei on barley.

Sampling Israeli populations. $B$. graminis f. sp. hordei isolates were collected before the peak of powdery mildew development. Three populations of the pathogen were sampled from wild barley. Five to eight single-colony isolates were collected from leaves in each of 19 niche sites at Ashquelon on 10 February 1997

Table 1. Set of barley differential lines, their genes for resistance to Blumeria graminis f. sp. hordei, and virulence frequency (\%) found at Israeli locations Ashquelon (A) in 1997 and Har'el (H) in 1997 and 1999 and in the Czech Republic (CZ) in 1997 and 1999

\begin{tabular}{|c|c|c|c|c|c|c|c|}
\hline No. & Differential line $^{a}$ & $\begin{array}{l}\text { Resistance } \\
\text { gene(s) }\end{array}$ & $\begin{array}{l}\text { A-97 } \\
(\%)\end{array}$ & $\begin{array}{c}\text { H-97 } \\
(\%)\end{array}$ & $\begin{array}{c}\text { CZ-97 } \\
(\%)\end{array}$ & $\begin{array}{c}\text { H-99 } \\
(\%)\end{array}$ & $\begin{array}{c}\text { CZ-99 } \\
(\%)\end{array}$ \\
\hline 1 & P01 & Mla1, MlaAl2 & 99 & 87 & 42 & 88 & 43 \\
\hline 2 & $\mathrm{P} 02$ & Mla3 & 88 & 96 & 19 & 91 & 19 \\
\hline 3 & P03 & Mla6, Mla14 & 86 & 95 & 84 & 82 & 86 \\
\hline 4 & P08B & Mla9 & 78 & 69 & 69 & 58 & 56 \\
\hline 5 & P19 & Mlp1 & 96 & 96 & 0 & 100 & 0 \\
\hline 6 & P20 & Mlat & 85 & 97 & 67 & 100 & 82 \\
\hline 7 & $\mathrm{P} 21$ & $M l g, M l C P$ & 4 & 9 & 96 & 16 & 99 \\
\hline 8 & P04B & Mla7, MlaNo3 & 0 & 2 & 100 & & \\
\hline 9 & $\mathrm{P} 10$ & Mla12, MlaEm2 & 97 & 98 & 77 & & \\
\hline 10 & P14 & Mlra & 99 & 100 & 100 & & \\
\hline 11 & P17 & Mlk1 & 98 & 100 & 74 & & \\
\hline 12 & P11 & Mla13, MlaRu3 & 0 & 0 & 51 & & \\
\hline 13 & P15 & MlRu2 & 100 & 100 & 98 & & \\
\hline 14 & $\mathrm{P} 23$ & $M l L a$ & 100 & 100 & 89 & & \\
\hline 15 & P24 & Mlh & 100 & 100 & 100 & & \\
\hline 16 & Pallas & Mla 8 & 100 & 100 & 100 & & \\
\hline 17 & RS170-47 × Kiebitz 1 & $\underline{\text { Mla17 }}^{\mathrm{b}}$ & & & & 48 & 0 \\
\hline 18 & RS20-1 $\times$ Kiebitz $^{1}$ & Mla18 & & & & 37 & 0 \\
\hline 19 & Diamant $^{2} \times 1 \mathrm{~B}-86 \mathrm{~B}$ & Mla19 & & & & 93 & 0 \\
\hline 20 & RS145-39 × Kiebitz 1 & Mla20 & & & & 99 & 0 \\
\hline 21 & Diamant $^{2} \times 1 \mathrm{~B}-20$ & Mla26 & & & & 99 & 0 \\
\hline 22 & RS1-8 $\times$ Piccolo $^{3}$ & Mla27 & & & & 10 & 0 \\
\hline 23 & Diamant $^{2} \times 1 \mathrm{~B}-151$ & $\overline{M l a 28}$ & & & & 98 & 0 \\
\hline 24 & RS110-4 × Sonja ${ }^{4}$ & Mla29 & & & & 92 & 0 \\
\hline 25 & Nigrate & $\overline{\text { Mla30, }}$ Mlni & & & & 79 & 0 \\
\hline 26 & RS142-29 $\times$ Dura $^{5}$ & Mla32 & & & & 97 & 0 \\
\hline 27 & RS42-6 $\times$ Oriol $^{6}$ & mlt1 & & & & 93 & 0 \\
\hline 28 & SG S-185 & $\overline{m l o}$ & & & & 0 & 0 \\
\hline 29 & $\mathrm{RS}^{137-28} \times$ Elgina $^{7}$ & $\underline{M l f 1}$ & & & & 0 & 0 \\
\hline 30 & RS42-8 $\times$ Oriol $^{6}$ & $\overline{M l i}$ & & & & 0 & 0 \\
\hline 31 & RS170-10 $\times$ Piccolo $^{3}$ & Mla25 & & & & 100 & 0 \\
\hline 32 & HSY-78 × Aramir ${ }^{8}$ & $\underline{\overline{M l j}}$ & & & & 100 & 0 \\
\hline \multicolumn{3}{|c|}{ No. of isolates } & 108 & 104 & 101 & 97 & 275 \\
\hline
\end{tabular}

(total of 108 isolates), four to six isolates from each of 20 niches at Har'el, on 11 February 1997 (total of 104 isolates), and four to eight isolates from each of 17 niches of Har'el on 15 March 1999 (total of 97 isolates).

Multiplication of inoculum from Israeli populations. The collected leaf segments with individual $B$. graminis f. sp. hordei colonies that had developed from natural infections were placed in petri dishes with $0.6 \%$ water agar and $35 \mathrm{ppm}$ benzimidazole, then incubated for 1 day at $20 \pm 2{ }^{\circ} \mathrm{C}$ under artificial light (cool-white fluorescent lamps providing $12 \mathrm{~h}$ light at $\left.15 \pm 5 \mu \mathrm{mol} \mathrm{m} \mathrm{m}^{-2} \mathrm{~s}^{-1}\right)$. Conidia from each colony were shaken onto two leaf segments, $25 \mathrm{~mm}$ in length, excised from the central part of healthy, fully expanded primary leaves of the cultivar Omer, a local old cultivar, used as universal suscept in Israel, and placed in closed plastic boxes $38 \times 57 \times 15 \mathrm{~mm}$ with $0.6 \%$ water agar and 35 ppm benzimidazole. Inoculated leaf segments were incubated under similar conditions for 13 to 18 days.

Location and sampling of Czech $B$. graminis f. sp. hordei populations. Conidia originating from cultivated barley fields were randomly sampled from the atmosphere by means of a mobile version of a jet spore sampler (37), which contained detached leaves in petri dishes with water agar. Susceptible barley line B-3213 (13) was used in 1997, and cv. Pallas was used in 1999 (30). Dishes were placed in the base of the spore sampler during sampling and then kept under laboratory conditions for 10 to 11 days $\left(20 \pm 3^{\circ} \mathrm{C}\right.$ under 8 $\mathrm{h}$ artificial light at $25 \pm 5 \mu \mathrm{mol} \mathrm{m} \mathrm{m}^{-2} \mathrm{~s}^{-1}$ ) to allow collected conidia to germinate. Conidia were sampled across the Czech Republic on 29 and 31 May 1997 and on 23 to 27 May 1999.

Population designation. The Ashquelon population of 1997 and the Har'el populations of 1997 and 1999 were abbreviated as A-97, H-97, and $\mathrm{H}-99$, respectively. The Czech populations of 1997 and 1999 were denoted CZ-97 and CZ-99.

Differential sets. The set of differentials used in 1997 (Table 1) was comprised of barley cv. Pallas and 15 near-isogenic 'Pallas' lines containing different genes for resistance to powdery mildew $(23,30)$. In 1999 , the set consisted of seven nearisogenic 'Pallas' lines, breeding line SG S185 , and cv. Nigrate, as well as 14 other lines carrying "new" genes conferring resistance to powdery mildew and derived from wild barley $(20,21,23,24,36)$.

Production of differential leaf segments. About 25 seeds of each differential were sown in a pot (90 $\mathrm{mm}$ upper diameter) filled with sand. Plants were grown in a greenhouse at $24 \pm 2^{\circ} \mathrm{C}$ for 13 to 18 days. Leaf segments $25 \mathrm{~mm}$ long were cut from the central part of healthy, fully expanded primary leaves. Three leaf segments of each differential were placed in a 
plastic box $(80 \times 125 \times 15 \mathrm{~mm})$ on $0.6 \%$ water agar with 35 ppm benzimidazole for testing each isolate.

Inoculation of differential leaf segments. In Israel, inoculation was performed in a metal tower measuring $85 \times$ $130 \mathrm{~mm}$ at the base and $350 \mathrm{~mm}$ high. For each isolate, a box with leaf segments from the differential set was placed at the bottom of the tower. Inoculum of each isolate collected from leaf segments was shaken onto a square piece $(30 \times 30 \mathrm{~mm})$ of black paper to control the amount of conidia, and blown through a hole in the side of the upper part of the inoculation tower. Inoculum density was ca. 15 conidia $\mathrm{mm}^{-2}$. The boxes with inoculated leaf segments were incubated for 10 days in an incubation room at $20 \pm 2{ }^{\circ} \mathrm{C}$ under artificial light (cool-white fluorescent lamps providing 12 $\mathrm{h}$ light at $15 \pm 5 \mu \mathrm{mol} \mathrm{m} \mathrm{m}^{-2} \mathrm{~s}^{-1}$ ).

Each colony that developed from conidia collected in the Czech Republic typically produced 15,000 to 25,000 conidia. The conidia of one colony were drawn into a replaceable tip of a varipipette AW 1000 set to $0.4-\mathrm{ml}$ volume and then blown out of the tip into a micro-settling tower using a syringe $(10 \mathrm{ml})$ and small tube. A dish with leaf segments from the differential set was at the bottom of the micro-settling tower. Inoculum density was about 3 conidia $\mathrm{mm}^{-2}$. Inoculation of leaf segments from differentials 17 to 32 (Table 1) in 1999 was carried out separately using five bulk isolates containing 23 to 59 colonies that developed from collected conidia. Dishes with inoculated leaf segments were kept under laboratory conditions $\left(20 \pm 3^{\circ} \mathrm{C}\right.$ under $8 \mathrm{~h}$ artificial light at $25 \pm 5 \mu \mathrm{mol} \mathrm{m} \mathrm{m}^{-2} \mathrm{~s}^{-1}$ ).

Virulence determination. Reaction type (RT) produced by each differential and $B$. graminis f. sp. hordei isolate combination was scored 8 or 9 days after inoculation on a 0 to 4 scale (40). This scoring scale was supplemented with RT $0(4)$ (i.e., RT 0 with a few RT 4 colonies) (22), which is characteristic for barley lines carrying the mlo resistance gene. Isolates that produced RT 3 or greater on a differential were considered virulent on the corresponding resistance gene(s). In cases where virulence was observed on a differential cultivar with two resistance genes, we concluded that the isolate had two corresponding virulence genes. But when an isolate was avirulent, one or both could be genes for avirulence. Thus, when scoring the frequencies in a population of such a virulence gene, the number of isolates virulent on the two combined resistance genes was deduced to be the least number of isolates with this particular virulence gene. Some isolates that were avirulent on the differential with two resistance genes may have had one but not both of the required virulence genes, so the actual frequency of a gene for virulence may have been greater than the calculated minimum frequency for that virulence.
Pathotype designation. The isolates were assigned numerical designations based on their virulence to matching resistance genes in the differentials 1 to 7 (Table 1). The differential set was divided into three groups: two triplets of differentials and one single differential. Each of the first two digits indicates virulence or avirulence on the three differentials of the respective triplet. If a virulence to the corresponding resistance gene is detected, the first differential line has the value $1\left(2^{0}\right)$, the second line has the value $2\left(2^{1}\right)$, and the third line has the value $4\left(2^{2}\right)$. Therefore, each digit can have a value from 0 (no virulence to any of the three differential lines) up to $7(=1+2+4$, virulent on each of the three differential lines). The last digit of the designation can be only 0 or 1 . The resulting number based on seven differentials defines the virulences of the isolates and consequently their classification as pathotypes $(16,31,32)$ (Table 2).

Data analysis. Descriptive parameters of populations (virulence frequency, viru- lence complexity, number of pathotypes, abundance, richness, and evenness) were calculated for the isolates with the HaGis program (18). In general terms, abundance signifies the frequency of the predominant pathotype (\%); richness defines the number of pathotypes identified as a proportion of the number of isolates tested; and evenness reflects the variation in frequencies of individual pathotypes, whereby a more even distribution of pathotypes results in a higher value of evenness. The relative virulence complexity was determined as virulence complexity per differential (29), and its average values per isolate also were computed.

Diversities within populations and distances between populations were measured for the seven populations by two types of indices based either on pathotype frequencies (the Shannon normalized diversity and the Rogers distance) or on both pathotype and virulence structure (the Kosman diversity and distance). Because of the importance of possible associations between loci

Table 2. Pathotypes of Blumeria graminis f. sp. hordei found on wild barley at Israeli locations Ashquelon (A) in 1997 and Har'el (H) in 1997 and 1999, their virulence complexity, and number of isolates

\begin{tabular}{|c|c|c|c|c|c|}
\hline \multirow[b]{2}{*}{ Pathotype $^{a, b}$} & \multirow{2}{*}{$\begin{array}{l}\text { Virulence } \\
\text { complexity }^{\mathrm{c}}\end{array}$} & \multicolumn{4}{|c|}{ Number of isolates } \\
\hline & & A-97 & H-97 & H-99 & Total \\
\hline 770 & 6 & 50 & 47 & 29 & 126 \\
\hline 760 & 5 & 17 & 22 & 21 & 60 \\
\hline 771 & 7 & 4 & 6 & 10 & 20 \\
\hline 370 & 5 & 7 & 2 & 7 & 16 \\
\hline 670 & 5 & & 9 & 5 & 14 \\
\hline 360 & 4 & 3 & 1 & 7 & 11 \\
\hline 570 & 5 & 6 & 3 & 2 & 11 \\
\hline 730 & 5 & 9 & 1 & & 10 \\
\hline 761 & 6 & & 2 & 4 & 6 \\
\hline 660 & 4 & & 2 & 3 & 5 \\
\hline 260 & 3 & & 2 & 1 & 3 \\
\hline 560 & 4 & 1 & & 2 & 3 \\
\hline 571 & 6 & & 1 & 2 & 3 \\
\hline 160 & 3 & 1 & & 1 & 2 \\
\hline 270 & 4 & 1 & & 1 & 2 \\
\hline 460 & 3 & & & 2 & 2 \\
\hline 530 & 4 & 2 & & & 2 \\
\hline 710 & 4 & 2 & & & 2 \\
\hline 740 & 4 & & 2 & & 2 \\
\hline 750 & 5 & & 2 & & 2 \\
\hline 170 & 4 & 1 & & & 1 \\
\hline 320 & 3 & 1 & & & 1 \\
\hline 350 & 4 & 1 & & & 1 \\
\hline 510 & 3 & 1 & & & 1 \\
\hline 520 & 3 & 1 & & & 1 \\
\hline 630 & 4 & & 1 & & 1 \\
\hline 720 & 4 & & 1 & & 1 \\
\hline No. of isolates & & 108 & 104 & 97 & 309 \\
\hline No. of pathotypes & & 17 & 16 & 15 & 27 \\
\hline$C / I^{d}$ & & 5.36 & 5.49 & 5.35 & 5.40 \\
\hline $\mathrm{C} / \mathrm{P}^{\mathrm{e}}$ & & 4.29 & 4.88 & 4.67 & 4.33 \\
\hline $\mathrm{C} / \mathrm{D}^{\mathrm{f}}$ & & 0.766 & 0.784 & 0.764 & 0.771 \\
\hline
\end{tabular}

${ }^{\text {a }}$ Classification of pathotypes is based on isolate virulence for seven differential lines (nos. 1 to 7 in Table 1).

${ }^{\mathrm{b}}$ Detailed data about pathotypes determined on all differentials used in a particular year are available from the first author.

c Number of virulences.

d Average virulence complexity per isolate.

e Average virulence complexity per pathotype.

${ }^{\mathrm{f}}$ Average of relative virulence complexity is defined as the average virulence complexity per isolate per differential. 
in B. graminis f. sp. hordei populations, indices based only on virulence frequencies were not considered. The Shannon normalized index of diversity within a population was first used in plant pathology by Andrivon and de Vallavieille (1) and was defined as follows:

$$
S h=\frac{-\sum_{i=1}^{n} p_{i} \ln p_{i}}{\ln N}
$$

where the numerator is the Shannon entropy index (38), $n=$ total number of pathotypes, $p_{i}=$ pathotype frequencies $(i=$ $1,2, \ldots, n)$, and $N=$ sample size. The Rogers distance between two populations (34) is expressed by the following formula:

$$
R=\frac{1}{2} \cdot \sum_{i=1}^{m}\left|p_{1 i}-p_{2 i}\right|
$$

where $m$ is the total number of pathotypes in both populations, and $p_{1 i}$ and $p_{2 i}(i=$ $1,2, \ldots, m)$ are frequencies of pathotype $i$ in the first and second populations, respectively. Calculations of the Kosman diversity $(K W)$ and distance $(K B)$ are complex, and the corresponding explanations can be found in Kosman (27), where these parameters were denoted as $K o$ and $K$, respectively.

All diversity and distance parameters were calculated using the bootstrap method across isolates (4). One hundred fictional samples for each population were created by the resampling process. Each fictional sample consisted of 100 isolates, which were drawn independently with replacement from an original population. The values of all diversity indices and distances were calculated for each fictional sample and pair of fictional samples, respectively. The mean of the 100 values obtained for each index/distance was considered as the corresponding index of diversity within a population or distance between populations. Differences between these means were deduced to be statistically significant at $\alpha=0.05$ using the Student $t$ test. All diversity parameters were computed using the KOIND package $(28,35)$.

The Fisher's exact test for contingency tables (39) was used for measuring association (disequilibrium) between pairs of virulences. The corresponding $\varphi$ coefficient of association between pairs of differentiating characters (formula 17.5 in Sokal and Rohlf [39]) was calculated using NTSYSpc package, version 2.1 (Exeter Software, Setauket, NY). In addition, the measure of correlation between pairs of differentials (loci) was also estimated (formula 1 in Kosman [29]) using the KOIND package.

Parameters for comparison of all populations were calculated on the basis of virulence patterns of isolates on the set of the following seven differential lines: P01, P02, P03, P08B, P19, P20, and P21 (Table 1).

\section{RESULTS}

The differentials used, their genes for resistance to powdery mildew, and frequencies of corresponding virulences found in the populations that were studied are presented in Table 1.

Israeli B. graminis f. sp. hordei populations. Ashquelon 1997. All 108 isolates contained virulences $R u 2, L a, h$, and $a 8$ (Table 1). In contrast, no virulences were found against the combined resistances Mla7, MlaNo3 or Mla13, MlaRu3, which were present in the differential lines P04B and P11, respectively, and the frequency of virulence to the combination $\mathrm{Mlg}, \mathrm{MlCP}$ (P21) was only $4 \%$. The virulence frequency detected on the other nine differentials ranged from 78 to $99 \%$.

Har'el 1997. All 104 isolates exhibited virulences $r a, k 1, R u 2, L a, h$, and $a 8$ (Table 1). Virulence to the combined Mla13, MlaRu3 (P11) was not detected. We found two isolates (2\%) virulent on P04B (Va7, VaNo3) and nine isolates virulent on $\mathrm{P} 21$ $(V g, V C P)$. The virulence frequency detected on the other seven differentials ranged from 69 to $98 \%$.

Ashquelon and Har'el, 1997. Frequencies of virulence among isolates from Har'el in 1997 were generally similar to those at Ashquelon. The greatest differences were that the frequency of virulence to the combined Mlal, MlaAl2 was $12 \%$ lower and the frequency of virulence to Mlat was $12 \%$ greater at Har'el than at Ashquelon in 1997.

Twenty-six pathotypes were detected among the 212 isolates from Ashquelon and Har'el in 1997 (Table 2). The eight most frequent pathotypes represented $88.2 \%$ of all isolates. Eleven pathotypes were each represented by only one isolate. The predominant pathotype 770 comprised $46.3 \%$ of the isolates from Ashquelon and $45.2 \%$ of the isolates from Har'el. Two other pathotypes found abundantly at Ashquelon (760 and 771) also occurred very frequently at Har'el. Pathotype 771 contains all seven virulences that were identified. Nineteen of the pathotypes were unique to either Ashquelon (10 pathotypes) or Har'el (9 pathotypes). Of these, the most abundant pathotype, designated 670, comprising nine isolates, was detected only at Har'el. Average complexity at Ashquelon (5.36) was slightly lower than at Har'el (5.49). In both populations, pathotypes with the lowest complexity were quite rare.

Har'el 1999. No matching virulence was found for the resistance gene mlo (Vo) originating from barley, or resistance genes Mlf1 (VfI) and Mli (Vi) derived from wild barley (Table 1). In contrast, all isolates had virulences Vpl and Vat as well as virulence against resistance genes Mla25 (Va25) and $M l j(V j)$ derived from wild barley. Virulence frequency to the other 16 mildew resistance genes ranged from 10 to $99 \%$. Based on the first seven differentials,
15 pathotypes were detected among 97 isolates (Table 1). The most frequently recorded (29 isolates) was again pathotype 770 (Table 2).

Har'el 1997 and 1999. Frequencies of virulence to differentials 1 to 7 at Har'el in 1999 were generally similar to those in 1997. The greatest differences were that the virulence frequency to the combined Mla6, Mlal4 was $13 \%$ lower, and the virulence frequency to the combined $\mathrm{Mlg}$, $M l C P$ was $7 \%$ greater in 1999 than in 1997.

Comparison of Israeli and Czech $B$. graminis f. sp. hordei populations. In 1997 and 1999, 309 isolates were obtained for study from three populations of $B$. graminis f. sp. hordei on plants of wild barley at two Israeli locations and 376 isolates were obtained for study from two Czech populations (CZ-97 and CZ-99) (Table 1). The data on pathotypes and their frequencies in the Czech populations are not presented here, but several parameters of populations and diversities were calculated for comparing with the Israeli populations (Table 3).

Out of a total of 27 pathotypes found in Israel, six of the eight most frequent pathotypes were found in all three populations comprising 244 isolates (79.0\%) (Table 2). There were 126 isolates $(40.8 \%)$ belonging to pathotype 770 , which was the most abundant in all three populations (29.9 to $46.3 \%$ ). No isolate of pathotype 670 was found at Ashquelon, whereas 14 such isolates were found at Har'el in both years. Nine isolates of pathotype 730 were found at Ashquelon in 1997, whereas only one isolate of 730 was found at Har'el.

Thirty-four pathotypes were found in the Czech Republic. Twenty-one pathotypes were found in both Czech populations, and 82 isolates $(21.8 \%)$ belonged to the most abundant pathotype 451. No common pathotype among the Israeli and the Czech populations was found.

Average virulence complexity per isolate $(\mathrm{C} / \mathrm{I})$ of the three Israeli populations (Table 3) was high and very similar (5.35 to 5.49 out of a possible seven maximum), while those for the two Czech populations were lower (3.77 and 3.84). Richness of the three Israeli populations was also very similar and quite low (0.154 to 0.157$)$, while those for one Czech population was relatively high (0.238) and the other was very low (0.113). Evenness of populations A-97 and H-97 was nearly identical, whereas evenness of population H-99 was higher. The evenness of population CZ-99 was similar to that of $\mathrm{H}-99$, but evenness for CZ-97 was much greater.

The Shannon normalized $(S h)$ and the Kosman $(K W)$ diversity indices were significantly different for the five populations (Table 3). The highest and the lowest diversities according to the indices were recorded for populations CZ-97 and H-97, respectively. The diversity of the Czech 
populations was much higher than that of the Israeli populations. The diversity for the CZ-97 population was higher than for CZ-99. The parameters for the populations of Ashquelon and Har'el in 1997, on the basis of 11 differentials, were similar. The diversities calculated on the basis of the reactions of 11 differentials were smaller compared with those based on the reactions of seven differentials.

Both the Rogers' $(R)$ and Kosman's $(K B)$ indices of distance between populations were significantly different for the six comparisons (seven differentials) (Table 4). Highest distances according to both indices were recorded between populations H-97 and CZ-97 and between H-99 and CZ-99, and the lowest distance was between H-97 and H-99. The Kosman distance between A-97 and H-97 calculated for 11 differentials was smaller than the Kosman distance calculated for seven differentials, but the Rogers' distance calculated for 11 differentials was greater than that for seven differentials.

Spatial distribution of diversity within Israeli locations. The diversity for clusters of niches at one location, Ashquelon, showed an interesting feature (Table 5). Diversity was the lowest in the cluster of niches near the cliffs (a) and increased toward the eastern cluster of niches (d). Diversity of the whole sample from all four clusters of niches was much higher than in the cluster near the cliffs, but lower than in the cluster in the east. At Har'el, the results were not consistent. In 1997, the diversity was larger in the northern fringe of the grove [cluster (b)] where it is cooler and more shaded; both these conditions favor B. graminis f. sp. hordei development compared with the southern fringe [cluster (d)], where it is warmer and sunnier. But in 1999, the situation was the reverse. However, the differences in pathotypes between the northern cluster and the southern cluster are quite marked, indicating that isolation by a stand of trees is quite effective.

\section{DISCUSSION}

Virulence frequencies. Long-term temporal changes in virulence in $B$. graminis $\mathrm{f}$. sp. hordei populations can be examined by comparing current results with those from a previous study on virulence that also included isolates from Har'el as well as four other locations in Israel. Among the 201 isolates from Har'el examined in the current study, we found frequencies of virulence to 12 resistance genes (Mla1, Mla3, Mla6, Mla7, Mla8, Mla9, Mla12, Mlat, Mlk1, MlLa, Mlra, and MlRu2) similar to those reported by Dinoor and Eshed 18 to 20 years earlier for the 63 isolates from this location in 1979-1980 that they studied (5). The frequencies of virulence to $\mathrm{mlo}, \mathrm{Mlg}$, and Mla13 in our study, however, differed from those found by Dinoor and Eshed. Although we found no isolates virulent to $m l o$, Dinoor and Eshed reported that $5 \%$ of their isolates from Har'el were virulent on one differential line with mlo, and $35 \%$ were virulent on a second line with mlo. They pointed out, however, that isolates that appeared virulent on $m l o$ in the virulence test could not be propagated on barley lines with mlo. It is possible, therefore, that the apparent virulence of these isolates may have been due to some environmental factors causing breakdown of the resistance in some of the differential plants with mlo.
We found that $9 \%$ of the isolates from Har'el were virulent on Mlg lines in 1997, and $16 \%$ were virulent in 1999 . Dinoor and Eshed (5) reported that $32 \%$ of their isolates from Har'el were virulent on $\mathrm{Mlg}$ lines. We did not find any virulence on the differential with combined resistance genes Mla13, MlaRu3 at either Har'el or Ashquelon, whereas Dinoor and Eshed found $25 \%$ of their isolates were virulent on 'Rupee', which contains Mla13 and MlaRu3 plus two other resistance genes. They also found that $38 \%$ of their isolates were virulent on 'Vagabond', which has Mla13 (15). Possible reasons for the large decline in frequency of virulence to $\mathrm{Mlg}$ and to Mla13 and MlaRu3 between 1979 and 1997 are not obvious. Cultivated barley is a minor crop in Israel, and furthermore, Mla13 was not introduced into Israeli barley cultivars. Our isolates were obtained from a site at Har'el a few hundred meters away from the site sampled by Dinoor and Eshed (5), because host plants at their site had in the meantime been eliminated by herbicide treatments. There were no physical barriers to spore movement between the site sampled in 1979 and the southern niche of the 1997 site, as this land had been planted to wheat, corn, or cotton, or left fallow. Tall trees likely created a barrier to spore movement between

Table 4. Distance between Israeli [Ashquelon (A) and Har'el (H)] and Czech (CZ) populations of Blumeria graminis f. sp. hordei in 1997 and 1999

\begin{tabular}{lccc}
\hline & & \multicolumn{2}{c}{ Distance between populations } \\
\cline { 3 - 4 } Populations & No. of differentials & Kosman, $\boldsymbol{K B}^{\mathbf{a}}$ & ${\text { Rogers, } \boldsymbol{R}^{\mathbf{b}}}$ \\
\hline A-97 and H-97 & $11^{\mathrm{c}}$ & 0.059 & 0.334 \\
A-97 and H-97 & $7^{\mathrm{d}}$ & 0.080 & 0.302 \\
A-97 and H-99 & 7 & 0.098 & 0.381 \\
H-97 and H-99 & 7 & 0.066 & 0.296 \\
H-97 and CZ-97 & 7 & 0.503 & 1.000 \\
H-99 and CZ-99 & 7 & 0.458 & 1.000 \\
CZ-97 and CZ-99 & 7 & 0.084 & 0.372 \\
\hline
\end{tabular}

a (27).

b (34).

c No. 1 to 11 in Table 1.

${ }^{d}$ No. 1 to 7 in Table 1.

Table 3. Comparison of Israeli populations of Blumeria graminis f. sp. hordei found at Ashquelon (A) in 1997 and Har'el (H) in 1997 and 1999 , and the Czech (CZ) populations of 1997 and 1999

\begin{tabular}{|c|c|c|c|c|c|c|c|}
\hline \multirow[b]{2}{*}{ Parameter } & \multicolumn{7}{|c|}{ Population } \\
\hline & A-97 & A-97 & H-97 & H-97 & H-99 & CZ-97 & CZ-99 \\
\hline Number of isolates & 108 & 108 & 104 & 104 & 97 & 101 & 275 \\
\hline Number of differentials concerned ${ }^{\mathrm{a}}$ & 7 & 11 & 7 & 11 & 7 & 7 & 7 \\
\hline Number of pathotypes & 17 & 20 & 16 & 19 & 15 & 24 & 31 \\
\hline Number of pathotypes with at least two isolates & 9 & 9 & 11 & 11 & 12 & 16 & 22 \\
\hline Abundance & 46.3 & 45.4 & 45.2 & 45.2 & 29.9 & 23.8 & 21.1 \\
\hline Average virulence complexity per isolate, $\mathrm{C} / \mathrm{I}$ & 5.36 & 8.29 & 5.49 & 8.49 & 5.35 & 3.77 & 3.84 \\
\hline Average of relative virulence complexity, C/D & 0.766 & 0.754 & 0.784 & 0.772 & 0.764 & 0.539 & 0.549 \\
\hline Richness (number of pathotypes/number of isolates) & 0.157 & 0.185 & 0.154 & 0.183 & 0.155 & 0.238 & 0.113 \\
\hline Evenness & 0.674 & 0.671 & 0.666 & 0.656 & 0.797 & 0.856 & 0.789 \\
\hline Shannon normalized index of diversity, $S h^{\mathrm{c}}$ & 0.398 & 0.415 & 0.364 & 0.410 & 0.459 & 0.847 & 0.568 \\
\hline Kosman's index of diversity, $K W^{\mathrm{c}}$ & 0.205 & 0.138 & 0.187 & 0.132 & 0.290 & 0.467 & 0.412 \\
\hline
\end{tabular}

${ }^{a}$ Used for pathotype formulas and calculations of parameters.

${ }^{\mathrm{b}}$ Frequency of the predominant pathotype (\%).

${ }^{c}$ Diversity indices were calculated by the KOIND package $(28,35)$ as averages on the basis of the bootstrap subsamples; the other indices were calculated by the HaGis program (18) on the original sample of the isolates. 
the northern niche sampled in 1997 and the 1979 site as well as the southern niche of 1997. On the other hand, we did not find virulence to the combination Mla13, MlaRu3 at either Har'el or Ashquelon, which is about $50 \mathrm{~km}$ from Har'el. It is doubtful, therefore, that a few hundred meters between the Har'el site sampled by Dinoor and Eshed and our site could account for the large difference in frequency of virulence to Mla13 and MlaRu3. Another possible explanation is that these resistance genes may have been present in the wild barley population at Har'el at a higher frequency in the 1970s than in the 1990s.

In the Israeli populations, we found considerably higher frequency of virulences for most resistance genes common in European barley cultivars (Val, Va3, Va6, Va9, Va12, Val3, Vk1, Vat, and VLa) (3) compared with the European populations $(19,42)$, and also a high frequency of virulence $V p l$, which is rarely recorded in Europe. In contrast, the frequency of the combined virulences $\mathrm{Va}$, VaNo3 and $\mathrm{Vg}$, $V C P$ were markedly lower in the three Israeli populations than in those from Europe (19).

The seven differentials that were selected to compare the five populations (three Israeli and two Czech ones) could potentially distinguish 128 (i.e., $2^{7}$ ) pathotypes. We found 27 pathotypes in the Israeli populations and 34 in the Czech populations, but no pathotype was common to both countries. The largest dissimilarity among pathotypes was revealed by the differential line P19 with resistance gene Mlp1. The frequency of the virulence Vpl in the Israeli populations was 96 to $100 \%$, whereas this virulence was never found in the Czech populations. The most likely explanation is that the gene $M l p l$ was not used in the breeding of any commercial European cultivar.

In 1999, we used differentials mostly from sources carrying "new" wild barley resistance genes against powdery mildew. These sources, originating from collections of wild barley in Israel, are now widely used, particularly by European breeders for developing barley cultivars resistant to powdery mildew. However, the frequency of virulences for these genes in the Israeli populations of the pathogen has not previously been determined. In 1999, we recorded a very high frequency of virulences for nine of these 14 resistance genes at Har'el, and a moderate frequency of virulences for three others. No isolate overcame the resistance genes Mlfl and Mli. However, the virulence frequencies of $V f l$ and $V i$, and also Va27 could be reduced by adopting other resistance genes such as Mla 7 and/or Mlg, which may be present in the corresponding differentials (Table 1).

Some virulences, e.g., $V g, V a 7$, and Val3, which are abundant in Europe (19), are absent or of low frequency in Israel. This suggests that the corresponding resistance genes in the host populations of wild barley in Israel could be present in low frequencies or absent. On the other hand, the high virulence frequencies found in the Israeli populations for the resistance genes Mla1, Mla3, Mla9, Mlat, Mla12, Mlra, Mlk1, MlRu2, MlLa, Mlh, and Mla8 suggest that these genes, derived from landraces, could also be present with others in the populations of wild barley in Israel.

A few correlated genes and weak associations between virulences for the set of seven old differentials were discovered in five of the investigated populations. However, the observed correlations and associations were not consistent between 1997 and 1999. Indeed, the two parameters, $\varphi$ coefficient of association and the measure of correlation, do not confirm sustainable associations between virulence genes in either the Har'el or the Czech populations.

Characteristics of the populations. According to the calculated distances, H97 and H-99 populations are the most similar (same location in different years), and A-97 and H-99 populations are the most dissimilar (different locations in different years) (Table 4). However, relative dissimilarities between the pairs of populations differ and depend on which index is used. The Rogers' genotypic distance $(R)$, which is based on the frequencies of pathotypes in the population, was least able to differentiate between pairs of populations, but it does not take into account degrees of similarity between the pathotypes. Using this index, A-97 and H-97 populations, and $\mathrm{H}-97$ and $\mathrm{H}-99$ populations were found to be almost equally dissimilar (the values of the Rogers' distance are 0.302 and 0.296 , respectively) despite the different reasons for the dissimilarity. H-97 and H-99 populations were dissimilar because the frequencies of most of the 11 common pathotypes were different (Table 2). On the other hand, A-97 and H97 populations were dissimilar because they shared just seven pathotypes, but the frequencies of the dominant pathotypes 770 and 760 were similar (Table 2). The Rogers' distance between A-97 and H-97 populations was higher for the set of 11 differentials compared with the set of seven (Table 4), due to the larger number of pathotypes discovered within these populations after testing the 11 differentials (Table 3).

According to the Kosman genetic distance $(K B)$, the dissimilarity between two populations from distant locations in the same season (A-97 and H-97) was 20\% larger (0.080) than that between two populations from the same location in two different years (H-97 and H-99; 0.066). This suggests that frequencies of virulence may be relatively stable within populations of B. graminis f. sp. hordei on wild hosts in Israel and that migration between distant populations is limited. In comparing the genetic distance among the three Israeli populations, we may conclude that the populations in different years at the same location are more similar than the populations of two locations in the same year. As expected, the genetic distance between populations of different countries was much larger than the distance between populations within each country.

The Kosman index of genetic diversity $(K W)$ was much smaller for 11 differentials than for seven differentials despite the fact that each additional differential could result in increasing diversity. The data in Tables 1 and 2 show that three of the additional differentials (nos. 9 to 11) are susceptible to most isolates and one (no. 8) is resistant to most isolates. Indeed, they differentiate only slightly among the isolates, and therefore, the addition of these four cultivars hardly changes the "absolute" diversity (diversity per se expressed

Table 5. Diversity in populations of Blumeria graminis f. sp. hordei in niches within two Israeli locations, Ashquelon (A) in 1997 and Har'el (H) in 1997 and 1999

\begin{tabular}{|c|c|c|c|c|c|c|c|c|c|c|c|}
\hline \multirow[b]{2}{*}{ Index } & \multicolumn{11}{|c|}{ Niches and populations (shaded) } \\
\hline & A-97a $a^{a}$ & $\mathbf{A}-97 \mathbf{b}^{\mathbf{a}}$ & A-97c ${ }^{a}$ & $A-97 d^{a}$ & A-97 & $\mathbf{H}-97 \mathbf{b}^{b}$ & H-97d ${ }^{b}$ & H-97 & H-99b ${ }^{b}$ & H-99d $d^{b}$ & H-99 \\
\hline$K W^{\mathrm{c}}$ & 0.149 & 0.194 & 0.226 & 0.259 & 0.205 & 0.235 & 0.140 & 0.187 & 0.228 & 0.295 & 0.290 \\
\hline$S h^{\mathrm{d}}$ & 0.293 & 0.295 & 0.389 & 0.432 & 0.398 & 0.367 & 0.303 & 0.364 & 0.358 & 0.463 & 0.459 \\
\hline No of isolates ${ }^{e}$ & 32 & 22 & 29 & 25 & 108 & 37 & 31 & 104 & 36 & 45 & 97 \\
\hline
\end{tabular}

${ }^{a}$ Four clusters of niches at Ashquelon, along a transect from the cliffs above the beach (a) to the east (b, c, and d; $d$ is the most eastern).

b Two niches on both sides of a grove at Har'el.

c Kosman's index of diversity within population. Diversity indices were calculated by the KOIND package (28,35) as averages on the basis of the bootstrap subsamples.

d Shannon's normalized index of diversity. Diversity indices were calculated by the KOIND package (28,35) as averages on the basis of the bootstrap subsamples.

e Total number of isolates included in the corresponding test. 
on seven differentials). However, the Kosman index measures diversity per differential, i.e., the "absolute" diversity divided by the number of differentials (11 and 7 , respectively). This explains why the $K W$ diversity measure produces lower values of diversity for the given set of 11 differentials than the set of seven, and why the values of Kosman's genetic distance $(K B)$ between populations have also decreased greatly by including these additional four differentials in calculating the distance index (Table 4).

According to Groth and Roelfs (17), a pathogen population is more diverse if: (i) that population consists of a larger number of phenotypes for a given number of isolates; (ii) it is characterized by an even distribution of phenotypes; or (iii) the number of differences in virulence between phenotypes is large. Properties (i) and (ii) are defined by the richness and evenness parameters, respectively, and the Shannon normalized index $(S h)$ takes into account both these properties (25). Increasing the number of differentials should result in an increase in the number of pathotypes detected in the population and, therefore, an increase in the measure of population richness. If the population evenness remains constant, the Shannon normalized index $(S h)$ should also increase as the number of differentials increases. Both trends were seen in this study, and this explains the higher values of the Shannon normalized index calculated from 11 differentials compared with seven (Table 3). Property (iii) may be expressed by the measure of average differences among isolates, where dissimilarity is measured by the simple mismatch coefficient.

Our expectation was that the diversity of B. graminis f. sp. hordei in Israel, which reflects the diversity of wild barley, would be larger than in Europe (e.g., the Czech Republic), where uniform host genotypes are grown over a large area. The findings were, however, quite different; both Czech populations were much more diverse than the Israeli populations as revealed by the average dissimilarity between the virulence patterns of isolates, property (iii) of Groth and Roelfs (17) (Table 3). Differences in virulence between isolates in the Czech populations were larger compared with the Israeli populations due to the virulence-avirulence ratio observed on differentials 1,2 , and 6 (Table 1). If one considers diversity with respect to any differential (33), then it is natural to assume that: (i) minimum diversity is observed when all isolates are either virulent or avirulent on this differential (the virulence-avirulence ratio equals infinity or 0 , respectively), and (ii) maximum diversity is observed when the numbers of virulent and avirulent isolates are equal (the virulence-avirulence ratio equals 1). Comparison of the Israeli and the Czech populations of $B$. graminis f. sp. hordei with respect to differentials 1,2 , and 6 revealed that the virulence-avirulence ratios were considerably closer to 1 for the Czech populations (Table 1), thereby indicating high diversity. For example, the virulenceavirulence ratio for $\mathrm{P} 01$ for the Czech CZ97 population was 0.724 (42/58), whereas for the Israeli $\mathrm{H}-97$ population it was 7.25 (87/13).

Evolutionary aspects. An important evolutionary force acting in pathogen populations is direct selection of virulences to resistance genes present in the host in a given area (9). Powdery mildew resistance genes present in barley cultivars grown in the Czech Republic were described in detail (12), and also the relative popularity of these cultivars over several years has been documented. Most wild barley accessions collected in Israel carry at least one resistance gene (10). Our recent investigations were aimed mainly at identifying sources possessing fully effective resistances (11). However, many other resistance genes, probably including wellestablished alleles, were detected (10).

The lower diversity in the Israeli pathogen populations, relative to the Czech populations, is due to the complete adaptation of virulence to resistance, which has probably reached its peak in Israel. Israel is part of the center of diversity of wild barley, and the Israeli host population is highly diversified and a rich source of genes conferring resistance to powdery mildew (14). Long-term natural selection in the Israeli populations of B. graminis $\mathrm{f}$. sp. horde $i$ has increased the frequencies of most virulence alleles to almost $100 \%$ and has created a center of virulence complexity of the pathogen.

Increasing virulence frequency is associated with rising complexity of the pathogen populations and evolution of so-called "super-races", which are virulent against a number of resistance genes. Our results demonstrate that such complex pathotypes are abundant in nature and confirms the effect of evolutionary forces on pathogen development even where there is high host and nonhost diversity.

Six virulences (Va1, Va3, Va6, Va9, Vat, and $V g$ ) studied in 1997 and 1999 and at least five other virulences (Va7, Va12, Va13, Vk1, and VLa) studied in 1997, which were effective against "old" resistance genes, came under intensive selection pressure in Europe, particularly in the Czech Republic, due to widespread growth of cultivars with the corresponding resistance genes (9). The adaptation of the Czech pathogen population also resulted in a huge increase in its virulence complexity against 11 corresponding resistance genes, and ranged from approximately 0.90 in 1971 to 7.89 in 2001 (8). However, virulence evolution in the Czech Republic has not advanced as far as in Israel, thereby maintaining higher diversity in the Czech pathogen population.
Based on the number of virulence genes that have already developed in B. graminis f. sp. hordei, it can be assumed that if newly discovered resistant genes are used individually in a new cultivar, this resistance will eventually, and likely quickly, be overcome due to spontaneous mutations in the pathogen population followed by selection on the new resistant cultivar. If several new resistant genes are deployed together in a new cultivar (pyramiding), it is anticipated that new pathotypes of $B$. graminis $\mathrm{f}$. sp. hordei with virulences matching the combination of resistance genes will not arise quickly because the probability that multiple random mutations will occur together, which is necessary to overcome two or more current fully effective resistance genes present jointly in one cultivar, is much less than the probability of a single mutation for virulence to one currently fully effective gene. However, this pathogen has demonstrated ability to develop complex pathotypes. Therefore, while it is recommended for breeding resistant barley cultivars to pyramid new genes that are fully effective in a given epidemiological area in order to prolong the durability of resistance, there will continue to be a need to search for new resistant genes and to monitor pathotypes in order to ensure farmers have cultivars that can effectively resist powdery mildew.

Clusters of niches at the two locations in Israel were studied to examine diversity within a location. Topography and local conditions explain the directional trend in diversity at Ashquelon and the effect of the physical barrier created by a stand of tall trees at Har'el. At Ashquelon, there is a diversity gradient increasing from the coast toward the east and corresponding to the prevailing wind, which constantly disperses pathogen spores. The data from Har'el show that diversity is significantly different on both sides of the large physical barrier (Table 5, niches $\mathrm{H}-97 \mathrm{~b}$ versus $\mathrm{H}$ 97d). It could be due to localized microevolution, aided by sexual recombination, without dispersal over the barrier.

This study revealed great differences between Israeli and Czech pathogen populations in the frequency of most virulences examined, and particularly virulences for "new" resistance genes originating from Israel. It establishes that both populations belong to distinct epidemiological units with little or no transfer of $B$. graminis $\mathrm{f}$. sp. hordei spores between them. This should stimulate the exploitation of host resistance diversity found in wild barley from Israel $(10,11)$ in breeding barley cultivars resistant to powdery mildew in Europe and throughout the world.

It is unlikely that significant exchange of inoculum between populations of $B$. graminis f. sp. hordei from Central Europe and the Middle East can occur by aerial dispersal (2) because of the natural barriers (mountains, Mediterranean Sea) and the 
distance between these two regions. There is, however, a risk of transferring isolates between isolated populations by human activities. As the results suggest, Israeli isolates exhibit high virulence complexity not only to most resistance genes possessed by current barley cultivars but also to new sources of resistance originating from Israel. One pathotype found at Har'el in 1999 was virulent against at least 12 "new" resistance genes. Pathotypes such as this should not be imported into Europe for research because of the serious threat to the successful long-term effort to collect, study, and utilize resistance from wild barley for developing European cultivars with durable resistance. Thus, research on such pathogenic cultures should be carried out in the area of their origin or, alternatively, plant material rather than pathogens could be brought from this area for testing (11).

The ability of $B$. graminis f. sp. hordei to adapt and evolve complex pathotypes, as revealed in this study, will limit the successful use of crop diversity through growing varietal mixtures for managing barley powdery mildew (41). Pyramiding resistance genes together in one cultivar is expected to be more successful. Success could be improved further with better understanding of pathogen evolution. Further research should focus on the time required for these highly complex pathotypes to evolve and to determine to what extent the adaptation process of pathogen populations has been slowed by host diversification.

\section{ACKNOWLEDGMENTS}

We thank Ahmed Jahoor, Risø National Laboratory, Roskilde, Denmark, for kindly providing barley differential lines. We acknowledge the financial support of the Colton Foundation, of Tel Aviv University, to Evsey Kosman. The first author thanks the Faculty of Agricultural, Food and Environmental Quality Sciences, Rehovot, for providing suitable conditions for both studying stays. This study was conducted within the grants 522/98/0196 and 522/03/0112 of the Czech Science Foundation.

\section{LITERATURE CITED}

1. Andrivon, D., and de Vallavieille-Pope, C. 1995. Race diversity and complexity in selected populations of fungal biotrophic pathogens of cereals. Phytopathology 85:897-905.

2. Brown, J. K. M., and Hovmøller, M. S. 2002. Aerial dispersal of pathogens on the global and continental scales and its impact on plant disease. Science 297:537-541.

3. Brown, J. K. M., and Jørgensen, J. H. 1991. A catalogue of mildew resistance genes in European barley varieties. Pages 263-286 in: Integrated Control of Cereal Mildews: Virulence and Their Change. J. H. Jørgensen, ed. Ris $\varnothing$ National Laboratory, Roskilde, Denmark.

4. Diaconis, P., and Efron, B. 1983. Computerintensive methods in statistics. Scientific American 249:116-130.

5. Dinoor, A., and Eshed, N. 1987. The analysis of host and pathogen populations in natural ecosystems. Pages 75-88 in: Populations of
Plant Pathogens: Their Dynamics and Genetics. M. S. Wolfe and C. E. Caten, eds. Blackwell Scientific Publications, Oxford.

6. Dinoor, A., and Eshed, N. 1990. Plant diseases in natural populations of wild barley (Hordeum spontaneum). Pages 169-186 in: Pests, Pathogens and Plant Communities. J. J. Burdon and S. R. Leather, eds. Blackwell Scientific Publications, Oxford.

7. Dinoor, A., Eshed, N., Ecker, R., GerechterAmitai, Z., Solel, Z., Manisterski, J., and Anikster, Y. 1991. Fungal diseases of wild tetraploid wheat in a natural stand in Northern Israel. Israel J. Bot. 40:481-500.

8. Dreiseitl, A. 2002. Virulence complexity and its increasing in the Czech population of Blumeria graminis f. sp. hordei. Proc. $6^{\text {th }}$ Conf. EFPP, 6th, Prague. Plant Prot. Sci. 38 (Special Issue 2):531-532.

9. Dreiseitl, A. 2003. Adaptation of Blumeria graminis f. sp. hordei to barley genetic resistance in the Czech Republic in 1971-2000. Plant Soil Environ. 49:241-248.

10. Dreiseitl, A., and Bockelman, H. E. 2003. Sources of powdery mildew resistance in a wild barley collection. Genet. Res. Crop Evol. 50:345-350.

11. Dreiseitl, A., and Dinoor, A. 2004. Phenotypic diversity of barley powdery mildew resistance sources. Genet. Res. Crop Evol. 51:251-257.

12. Dreiseitl, A., and Jørgensen, J. H. 2000. Powdery mildew resistance in Czech and Slovak barley cultivars. Plant Breed. 119:203-209.

13. Dreiseitl, A., and Steffenson, B. J. 1996. Postulation of powdery mildew resistance genes in North American barley cultivars. Barley Newsl. 40:82-90.

14. Fischbeck, G., Schwarzbach, E., Sobel, Z., and Wahl, I. 1976. Mehltauresistenz aus Israelischen Populationen der Zweizeiligen Wildgerste (Hordeum spontaneum). Zeitschr. Pflanzenzücht. 76:163-166.

15. Giese, H. 1981. Powdery mildew resistance genes in the $M l-a$ and $M l-k$ regions on barley chromosome 5. Hereditas 95:51-62.

16. Gilmour, J. 1973. Octal notation for designating physiologic races of plant pathogens. Nature 242:620.

17. Groth, J. V., and Roelfs, A. P. 1987. The concept and measurement of phenotypic diversity in Puccinia graminis on wheat. Phytopathology 77:1395-1399.

18. Hermann, A., Löwer, C. F., and Schachtel, G. A. 1999. A new tool for entry and analysis of virulence data for plant pathogens. Plant Pathol. 48:154-158.

19. Hovmøller, M. S., Caffier, V., Jalli, M., Andersen, O., Besenhofer, G., Czembor, J. H., Dreiseitl, A., Felsenstein, F., Fleck, A., Heinrics, F., Jonsson, R., Limpert, E., Mercer, P., Plesnik, S., Rashal, I., Skinnes, H., Slater, S., and Vronska, O. 2000. The European barley powdery mildew virulence survey and disease nursery 1993-1999. Agronomie 20:729-743.

20. Jahoor, A., and Fischbeck, G. 1987. Sources of resistance to powdery mildew in barley lines derived from Hordeum spontaneum collected in Israel. Plant Breed. 99:274-281.

21. Jahoor, A., and Fischbeck, G. 1993. Identification of new genes for mildew resistance of barley at the Mla locus in lines derived from Hordeum spontaneum. Plant Breed. 110:116-122.

22. Jensen, H. P., Christensen, E., and Jørgensen, J. H. 1992. Powdery mildew resistance genes in 127 Northwest European spring barley varieties. Plant Breed. 108:210-228.

23. Jørgensen, J. H. 1994. Genetics of powdery mildew resistance in barley. Crit. Rev. Plant
Sci. 13:97-119.

24. Kintzios, S., Jahoor, A., and Fischbeck, G. 1995. Powdery-mildew-resistance genes Mla29 and Mla32 in H. spontaneum derived winter-barley lines. Plant Breed. 114:265-266.

25. Kolmer, J. A., Long, D. L., Kosman, E., and Hughes, M. E. 2003. Physiologic specialization of Puccinia triticina on wheat in the United States in 2001. Plant Dis. 87:859-866.

26. Koltin, Y., and Kenneth, R. 1970. The role of the sexual stage in the oversummering of Erysiphe graminis DC. f. sp. hordei Marchal under semi-arid conditions. Ann. Appl. Biol. 65:263-268.

27. Kosman, E. 1996. Difference and diversity of plant pathogen populations: A new approach for measuring. Phytopathology 86:1152-1155.

28. Kosman, E. 2002. Koind - package of programs for calculating diversities within populations, distances between populations and measure of gene linkage. Petria 12 (1/2):249252.

29. Kosman, E. 2003. Measure of multilocus correlation as a new parameter for study of plant pathogen populations. Phytopathology 93:1464-1470.

30. Kølster, P., Munk, L., Stølen, O., and Løhde, J. 1986. Near-isogenic barley lines with genes for resistance to powdery mildew. Crop Sci. 26:903-907.

31. Limpert, E., Clifford, B., Dreiseitl, A., Johnson, R., Müller, K., Roelfs, A., and Wellings, C. 1994. Comparing systems of designation of pathotypes of plant pathogens. J. Phytopathol. 140:359-362.

32. Limpert, E., and Müller, K. 1994. Designation of pathotypes of plant pathogens. J. Phytopathol. 140:346-358.

33. Manisterski, J., Eyal, Z., Ben-Yehuda, P., and Kosman, E. 2000. Comparative analysis of indices in the study of virulence diversity between and within populations of Puccinia recondita f. sp. tritici in Israel. Phytopathology 90:601-607.

34. Rogers, J. S. 1972. Measures of genetic similarity and genetic distance. Pages 145-153 in: Studies in Genetics. University of Texas, Austin.

35. Schachtel, G. A., and Kosman, E. 2002. KOIND package - short manual. Biometrie \& Populationsgenetic, JLU Giessen. Online publication: http://www.va-tipp.de.

36. Schönfeld, M., Ragni, A., Fischbeck, G., and Jahoor, A. 1996. RFLP mapping of three new loci for resistance genes to powdery mildew (Erysiphe graminis f. sp. hordei) in barley. Theor. Appl. Genet. 93:48-56.

37. Schwarzbach, E. 1979. A high throughput jet trap for collecting mildew spores on living leaves. Phytopathol. Zeitschr. 94:165-171.

38. Shannon, C. E., and Weaver, W. 1949. The Mathematical Theory of Communication. University of Illinois, Urbana.

39. Sokal, R. R., and Rohlf, F. J. 1995. Biometry. W. H. Freeman, New York.

40. Torp, J. H., Jensen, P., and Jørgensen, J. H 1978. Powdery mildew resistance genes in 106 Northwest European spring barley varieties. Pages 75-102 in: Royal Veterinary and Agricultural University, Copenhagen, Denmark, Yearbook 1978

41. Wolfe, M. S. 2000. Crop strength through diversity. Nature 406:681-682.

42. Wolfe, M. S., Brändle, U., Koller, B., Limpert, E., McDermott, J. M., Müller, K., and Schaffner, D. 1992. Barley mildew in Europe: Population biology and host resistance. Euphytica 63:125-139. 